This item was submitted to Loughborough's Research Repository by the author.

Items in Figshare are protected by copyright, with all rights reserved, unless otherwise indicated.

\title{
Measurement and characterisation of radiated underwater sound from a 3.6
} MW monopile wind turbine

\section{PLEASE CITE THE PUBLISHED VERSION}

http://dx.doi.org/10.1121/1.4964824

\section{PUBLISHER}

(C) Acoustical Society of America

VERSION

VoR (Version of Record)

\section{LICENCE}

CC BY-NC-ND 4.0

\section{REPOSITORY RECORD}

Pangerc, Tanja, Pete D. Theobald, Lian-Sheng Wang, Stephen P. Robinson, and Paul Lepper. 2019.

"Measurement and Characterisation of Radiated Underwater Sound from a 3.6 MW Monopile Wind Turbine". figshare. https://hdl.handle.net/2134/23368. 


\title{
Measurement and characterisation of radiated underwater sound from a 3.6 MW monopile wind turbine
}

\author{
Tanja Pangerc, ${ }^{\text {a) }}$ Peter D. Theobald, Lian S. Wang, and Stephen P. Robinson \\ Acoustics and Ionising Radiation, National Physical Laboratory, Hampton Road, \\ Teddington TW11 0LW, United Kingdom \\ Paul A. Lepper \\ Department of Electronic and Electrical Engineering, Loughborough University, Loughborough, \\ Leicestershire LE11 3TU, United Kingdom
}

(Received 18 December 2015; revised 26 September 2016; accepted 3 October 2016; published online 26 October 2016)

\begin{abstract}
This paper describes underwater sound pressure measurements obtained in close proximity $(\sim 50 \mathrm{~m})$ to two individual wind turbines, over a 21-day period, capturing the full range of turbine operating conditions. The sound radiated into the water was characterised by a number of tonal components, which are thought to primarily originate from the gearbox for the bandwidth measured. The main signal associated with the turbine operation had a mean-square sound pressure spectral density level which peaked at $126 \mathrm{~dB}$ re $1 \mu \mathrm{Pa}^{2} \mathrm{~Hz}^{-1}$ at $162 \mathrm{~Hz}$. Other tonal components were also present, notably at frequencies between about 20 and $330 \mathrm{~Hz}$, albeit at lower amplitudes. The measured sound characteristics, both in terms of frequency and amplitude, were shown to vary with wind speed. The sound pressure level increased with wind speed up to an average value of $128 \mathrm{~dB}$ re $1 \mu \mathrm{Pa}$ at a wind speed of about $10 \mathrm{~ms}^{-1}$, and then showed a general decrease. Overall, differences in the mean-square sound pressure spectral density level of over $20 \mathrm{~dB}$ were observed across the operational envelope of the turbine. [http://dx.doi.org/10.1121/1.4964824]
\end{abstract}

[APL]

Pages: 2913-2922

\section{INTRODUCTION}

At the end of 2015, the United Kingdom had over 1450 operational offshore wind turbines, with nearly 2000 further offshore wind turbines either under construction or consented (RenewableUK, 2015). The trend is mirrored globally, with the number of wind turbines expected to increase (Global Wind Council, 2015). This has the potential to radiate underwater noise into the marine environment, with concerns over the potential impacts of underwater noise on the marine environment reflected within legislation; the Marine Strategy Framework Directive (European Parliament and Council, 2008) considers underwater noise a pollutant; the EU Habitats Directive (European Council, 1992) and the US Marine Mammal Protection Act (MMPA) connect underwater noise with wildlife legislation.

The first offshore wind turbine was installed in 1990 in Sweden (Bilgili et al., 2011). Since then, several accounts of underwater sound associated with an operational wind turbine have been published in research reports (Westerberg, 1994; Degn, 2000; Lindell, 2003; Nedwell et al., 2004; Thomsen et al., 2006; Nedwell et al., 2007; Nedwell et al., 2011a,b), a number of which are reviews or compilations of the same datasets for the purposes of assessing the noise impact on marine life. Madsen et al. (2006) completed a review of some of the available data concluding that the resulting underwater noise is unlikely to impair hearing in marine mammals. Wahlberg and Westerberg (2005) also

\footnotetext{
${ }^{a)}$ Electronic mail: tanja.pangerc@npl.co.uk
}

used some of these previously measured data to assess the potential impact on fish around operational wind turbines. Further accounts of underwater noise measurements from operational wind turbines have also been reported in conference proceedings (Betke et al., 2004; Cheesman, 2016; Norro et al., 2015). Koschinski et al. (2003) and Tougaard et al. (2009) published underwater sound pressure measurements of offshore wind turbines in the peer-reviewed literature primarily with acoustic data presented in one-third octave bands to assess the potential for impact on seals and harbour porpoise. Koschinski et al. (2003) measured simulated $2 \mathrm{MW}$ wind turbine noise, while Tougaard et al. (2009) measured the sound radiated from offshore wind turbines with rated capacity between $0.45 \mathrm{MW}$ to $2 \mathrm{MW}$. Overall, the available data include measurements for wind turbines with rated capacity between 0.22 to $5 \mathrm{MW}$, and with gravity, tripod and monopole foundations, in water depths between about 6 and $20 \mathrm{~m}$. The study reported here is of a Siemens 3.6 MW SWT-3.6-107 turbine, one of the most widely used in Europe. This particular turbine has been the subject of measurements reported in commercial reports (e.g., Nedwell et al., 2011a,b) and their general characteristics were summarised by Cheesman (2016), although the existing data come from a range of snapshot measurements. In general, most of the data reported in the literature were collected as a series of discrete measurements, generally a few minutes in length, with the collective measurement time spanning a few hours or days. Some of the earlier studies, however, comprised longer term data collection, although data analysis concentrated on subsets of the measured data (e.g., Degn, 2000; Betke et al., 2004). One study focussed on particle 
motion measurements from an offshore wind turbine (Sigray and Andersson, 2011).

The sound associated with wind turbine operation has, in general, been described as continuous in nature, and characterised by one or more tonal components typically at frequencies below $1000 \mathrm{~Hz}$ (Degn, 2000; Betke et al., 2004; Madsen et al., 2006; Wahlberg and Westerberg, 2005; Tougaard et al., 2009; Sigray and Andersson, 2011). For turbines with a staged gearbox system, the noise output has been found to vary with wind speed, and wind-driven turbine parameters, including blade revolution, and gearbox and generator rate of operation (Madsen et al., 2006; Betke et al., 2004; Sigray and Andersson, 2011). The correlation of mechanical vibrations of the turbine tower with sound pressure and particle motion measurements in the water column demonstrated by Lindell (2003), and Sigray and Andersson (2011), respectively, corroborated the view that the origin of turbine noise lie in mechanical vibrations in the nacelle, which are transmitted down to the turbine foundation, and originate from the rotation of the wind-powered components in the nacelle. This has been supported with modelling (Marmo et al., 2013).

Some of the previous studies have investigated the relationship between wind speed induced rotation of the turbine components and the radiated underwater noise characteristics during particular wind conditions (Lindell, 2003; Betke, 2004; Tougaard et al., 2009; Sigray and Andersson, 2011), but none examined the temporal variations over a full range of operational conditions. The methodology adopted for this paper allows acoustic measurement data of the sound radiated into the water to be obtained for nominally identical wind turbines, within the same wind farm, over their full range of operational states. The acoustic characteristics of the sound radiated into the water from two individual turbines for a period of 21 days are therefore quantified over the turbine's full power envelope from the cut-in wind speed, through ramp up of the turbine output power, to its maximum operating power and its cut-out wind speed. These are new, robust data, which are not based on snapshot measurements, and that have been obtained with calibrated instrumentation demonstrated to have a suitably low noise floor for measuring the acoustics conditions present during the study. The results provide detailed acoustic characteristics of an operational offshore wind turbine, and show a relatively complex relationship between the sound radiated into the water and wind speed, particularly around the optimal operating wind speed for the turbine. No attempts are made to estimate the sound field at any other position than those measured, and it is not the purpose of this paper to make any assumptions about the potential for impact on marine fauna, although the reference data presented in this paper are expected to facilitate improved confidence in such assessments.

\section{MEASUREMENT LOCATION AND SET UP}

\section{A. Wind farm}

The measurements were performed at the Sheringham Shoal offshore wind farm, which is located in the UK coastal waters, about $20 \mathrm{~km}$ offshore of the Norfolk coast. It comprises 88 wind turbines, each with a $3.6 \mathrm{MW}$ power rating. Figure 1 shows the offshore wind farm layout and individual wind turbine positions. The turbine model used throughout the offshore wind farm is the Siemens SWT-3.6107 (Siemens, Germany), supported by 4.2 to $5.2 \mathrm{~m}$ diameter steel monopiles. The turbine has a three blade rotor, and is equipped with a three stage planetary/helical gearbox, with $1: 119$ ratio. It operates on a variable rotor speed regulation at 5 to $13 \mathrm{rpm}$, and reaches the nominal maximum power output of $3.6 \mathrm{MW}$ at wind speed of 13 to $14 \mathrm{~ms}^{-1}$. A wind speed of between 3 and $5 \mathrm{~ms}^{-1}$ is required to generate power (cut-in speed), and the turbine cut-out wind speed is $25 \mathrm{~ms}^{-1}$.

The seabed around the wind farm is generally coarse sediment with the foundations predominantly installed in layers of clay, and sand, with some of the foundations terminating in a chalk layer. The nominal water depth across the wind farm site varies between around 16 to $22 \mathrm{~m}$ with tidal variations resulting in up to around $4 \mathrm{~m}$ rise in water level, depending on the time of the year. The bathymetry within the wind farm is relatively uniform compared with the areas surrounding the wind farm site, which are characterised by both deeper channels and intermittent sandbanks. The deeper areas are frequented by shipping traffic that runs in a roughly east-westerly direction approximately $10 \mathrm{~km}$ north and about $6 \mathrm{~km}$ south of the offshore wind farm.

\section{B. Measurement equipment}

All acoustic measurements reported here were obtained using two DSG-Ocean Acoustic Dataloggers (Loggerhead Instruments), configured to log data directly to a digital solid state recording device. Prior to use, the acoustic pressure sensitivity and acoustic equivalent noise floor of the instrument were tested. The sensitivity tests were performed in a $5 \mathrm{~m}$ deep cylindrical test tank with a $5.5 \mathrm{~m}$ diameter by comparing the DSG-Ocean Acoustic Dataloggers to a reference hydrophone (Reson TC4040, Teledyne Reson, Denmark), which had previously been calibrated traceable to national standards at the National Physical Laboratory (NPL). During the calibration, the reference hydrophone and the DSG-Ocean

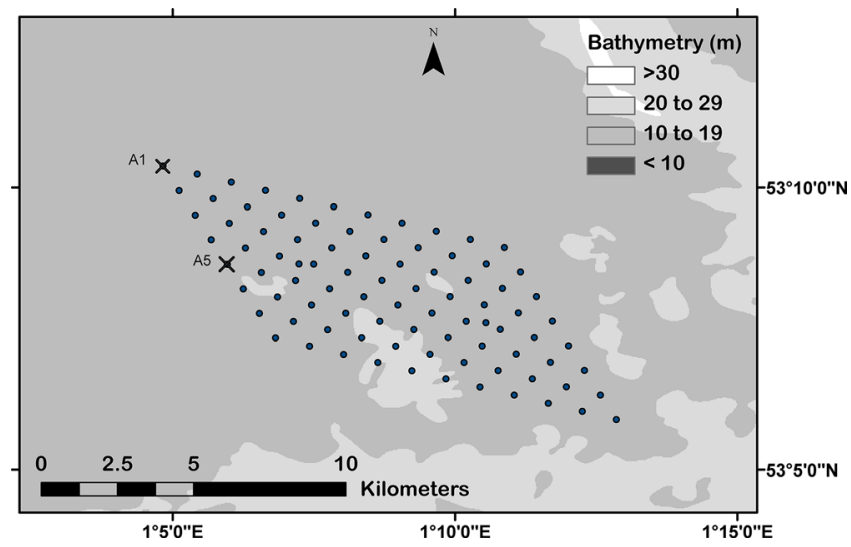

FIG. 1. (Color online) Schematic of the offshore wind farm constituting 88 wind turbines and two offshore meteorological mast installations (circles). Measurements were obtained about $50 \mathrm{~m}$ west from a turbine location, for turbine $\mathrm{A} 1$ and $\mathrm{A} 5$ whose positions within the windfarm are marked by a cross. 
Acoustic Dataloggers were precisely positioned to be at the same point in the acoustic field of the source transducer. The tests were performed for a range of discrete frequency tonebursts from 1 to $40 \mathrm{kHz}$, in $1 \mathrm{kHz}$ steps. The tone-burst length was chosen to allow measurements to be performed on the steady-state portion of the waveform before the arrival of reflections from the boundaries of the tank, thus approximating a free-field as described in IEC (2006). To test the lower frequencies sensitivity of the DSG-Ocean Acoustic Dataloggers, a comparison against a reference microphone was performed in a closed chamber coupler system. As the dimensions of the chamber are substantially smaller than the wavelength of the sound, the pressure change in the chamber is uniform throughout the chamber. This allowed testing of the DSG-Ocean Acoustic Datalogger sensitivity between $25 \mathrm{~Hz}$ and $400 \mathrm{~Hz}$.

The tests showed that the sensitivities of the two DSGOcean Acoustic Datalogger devices agreed within around $1 \mathrm{~dB}$ of each other, but that differences in sensitivity could be expected from the supplied nominal sensitivity of between 1 and $2.5 \mathrm{~dB}$ between 1 and $10 \mathrm{kHz}$. The testing between 25 and $400 \mathrm{~Hz}$ showed similar differences with a consistently lower measured sensitivity than the nominal value provided by the manufacturer. The nominal sensitivity provided and the sensitivity obtained during testing both included the hydrophone sensitivity, gain, and other signal processing on the DSG-Ocean Acoustic Datalogger devices.

It should be noted that the free-field measurements performed on the DSG-Ocean Acoustic Datalogger will include multi-paths or reflections from the body of the device, which will have a frequency dependent effect on both the sensitivity and the directivity of the device (Hayman et al., 2016). This will also be present when the device is used in situ, but would not be included in the low-frequency coupler measurements. Given the uncertainty associated with the actual in situ response of the device, or its precise orientation to source, this paper reports the absolute sound pressure levels using the supplied nominal sensitivity, and potential for uncertainty should be noted.

To determine the suitability of the DSG-Ocean Acoustic Datalogger for the measurement of underwater sound radiated from an operational turbine, the acoustic equivalent noise floor of these devices was measured in an acoustic test chamber which has a measured acoustic noise floor generally less than $0 \mathrm{~dB}$ re $20 \mu \mathrm{Pa}$ with A-weighting applied. These tests demonstrated that the devices under test had acoustic equivalent noise floor levels comparable to sea state zero levels published by Wenz (1962), for the relevant frequencies, which can be considered sufficiently low for the measurement of sound radiated from operational wind turbines which are situated in areas of sea where higher sea-states would generally be expected to prevail.

\section{Measurement procedure}

Whilst these measurements were performed as part of a broader requirement to carry out measurements of the underwater sound radiated from the operational wind farm, this paper describes work specifically to measure the variation in the underwater acoustic characteristics of the wind turbines during varying operating states, i.e., rotational speed and wind speed. To do this, underwater sound measurements were obtained during April and May 2013, at two locations adjacent to two different wind turbines. The turbine locations are indicated in Fig. 1 and labelled according to their designated unique identifier within the wind farm (A1 and A5, respectively). The turbines $\mathrm{A} 1$ and $\mathrm{A} 5$ are located in a nominal water depth of about 16 and $19 \mathrm{~m}$, respectively. Each DSG-Ocean Acoustic Datalogger was tethered from a $75 \mathrm{~kg}$ anchor weight, approximately $50 \mathrm{~m}$ from each turbine, and floated around $4 \mathrm{~m}$ above the seabed using a small subsurface float around $2 \mathrm{~m}$ above the recording unit. The distance between turbine and acoustic recorder deployment position was determined using nautical charts and Geographic Information System positioning information, and confirmed by laser ranging relative to turbine. The location of the anchor weight was marked with a surface float on a separate line to ensure that the recorder and hydrophone were decoupled from the surface motion. The autonomous recorders were left in place to measure the underwater sound pressure over a period of 21 days, using a sample rate of 7017.54 samples per second, default system gain of $20 \mathrm{~dB}$ and a 16-bit digital dynamic range, providing a maximum measurement bandwidth of approximately $3.5 \mathrm{kHz}$. The recorders were configured to acquire data for $30 \mathrm{~min}$, with a 1 min pause before recording again, and the data were stored in an uncompressed WAV file format. It should be noted that all acoustic metrics were chosen to be consistent with ISO (2016).

\section{Non-acoustic data}

Turbine operational information was provided by Scira Offshore Energy, Ltd. for a number of parameters, including wind speed (around $80 \mathrm{~m}$ above the sea surface), and rotational speed of turbine and generator. The data were provided as discrete values recorded every $10 \mathrm{~min}$ for the duration of the acoustical measurements. The tidal height information was obtained from the British Oceanographic Data Centre, from the tidal gauge for Cromer, at $15 \mathrm{~min}$ intervals.

\section{RESULTS AND ANALYSIS}

\section{A. Analysis method}

All data were analysed in MATLAB $11 \mathrm{~b}$ (v7.13.0.564, Mathworks, Inc.). The measured acoustic data at each of the autonomous acoustic recorders have been analysed for a period when the recorders were deployed underwater. The time domain data were converted into mean-square sound pressure spectral density (or power spectral density) using Welch's method (Welch, 1967), before applying corrections for the hydrophone sensitivity as a function of frequency across the entire frequency range of interest and for the system gain. Unless otherwise stated, power spectral density level, with units of $\mathrm{dB}$ re $1 \mu \mathrm{Pa}^{2} \mathrm{~Hz}^{-1}$, will be used as a proxy for mean-square sound pressure spectral density level. Similarly, power spectral level will be used as a proxy for mean-square sound pressure spectral level with units of $\mathrm{dB}$ re $1 \mu \mathrm{Pa}^{2}$ 
Each 30 min recording file was broken down into three, 10 min periods, analysed using the Welch's method for a $1 \mathrm{~s}$ non-overlapping Hanning window for a $10 \mathrm{~min}$ record length. For convenience of showing the complete dataset in spectrogram displays, all $30 \mathrm{~min}$ segments have been plotted as a continuous spectrogram over the 21-day period by removing the $1 \mathrm{~min}$ recording pause between each $30 \mathrm{~min}$ recording file. It should be noted that the use of a $1 \mathrm{~s}$ window will result in higher uncertainty of the lower frequency bands and for this reason, measurement data below $10 \mathrm{~Hz}$ have generally been excluded. One-third octave bands (base 2) were calculated to be consistent with ANSI S1.1-1986 (ASA 65-1986) (American National Standards Institute, 2008). Broadband acoustical data are calculated as sound pressure level (SPL), also known as root-mean-square sound pressure level, for a bandwidth between $40 \mathrm{~Hz}$ and the Nyquist frequency. The SPL was derived from the mean-square sound pressure spectral levels averaged over $10 \mathrm{~min}$ as described above, and is reported as an un-weighted quantity.

\section{B. Turbine operational data}

The non-acoustic data for wind speed and turbine operation showed a strong positive association. This is exemplified in Fig. 2 where the turbine rotational speed, wind speed and generator speed are plotted over the entire deployment duration. As the wind speed increased, the generator and rotor revolutions increased, plateauing above about 1600 and $13 \mathrm{rpm}$, respectively, when nominal power generation was reached at around 13 to $14 \mathrm{~ms}^{-1}$ winds.

The maximum measured wind speed was $27.2 \mathrm{~ms}^{-1}$, and was simultaneously logged at both turbines on April 18. The corresponding wind speed rotation and generator speed were, $13 \mathrm{rpm}$ and $1619 \mathrm{rpm}$, respectively. The lowest logged wind speed was $0 \mathrm{~ms}^{-1}$. This was observed on various occasions throughout the deployment duration, and typically did not persist. The wind speed was most frequently logged between 5 and $8 \mathrm{~ms}^{-1}$, and for much of the time the logged values remained below $14 \mathrm{~ms}^{-1}$.

\section{Acoustical data}

The top panel in Figs. 3 and 4 shows spectrograms for the measured acoustical data obtained at the two wind turbines. These were obtained using the method described in

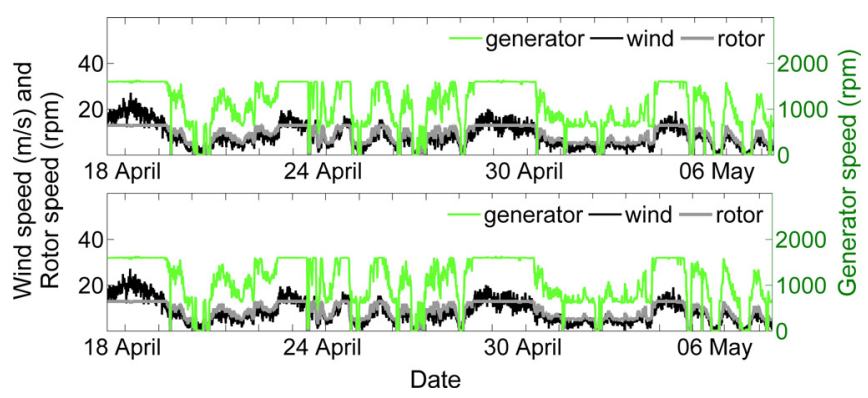

FIG. 2. (Color online) The time series data for wind speed, rate of turbine blade rotation and the turbine generator speed for turbine A1 (top) and A5 (bottom). The data are plotted for the duration of acoustical data analysed and presented here.
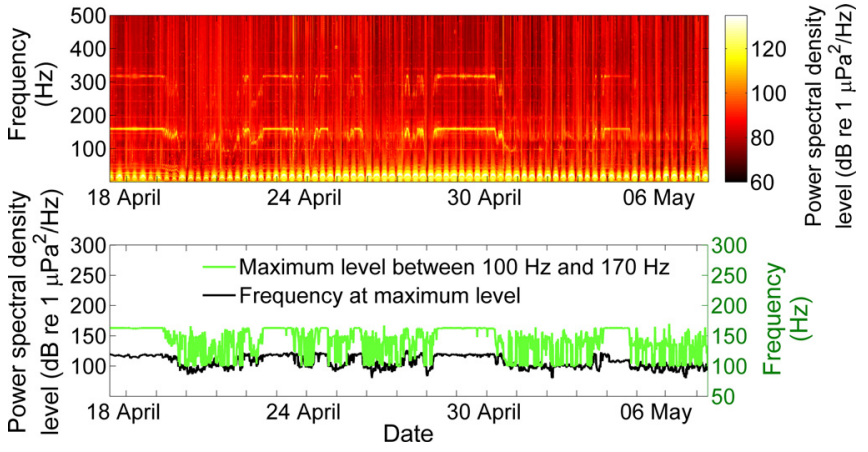

FIG. 3. (Color online) Spectrogram of underwater sound measured about $50 \mathrm{~m}$ from wind turbine A1 showing the frequency and amplitude during the 21-day deployment (top). The spectrogram display has been plotted up to $500 \mathrm{~Hz}$ for clarity. The lower panel shows the maximum mean-square sound pressure spectral density level (power spectral density level) between 100 and $170 \mathrm{~Hz}$ plotted alongside the corresponding frequency data.

Sec. III A to show the power spectral density level for each turbine as a function of time over the duration of the measurement period (21 days).

The power spectral density level analysis captures the turbines operating across a range of the power generating conditions from their minimum to maximum, and also includes periods when wind farm servicing vessels were on site. For both turbines, the spectrograms show that the acoustic power is concentrated in a narrow range of frequencies, with most tonal energy between 100 and $170 \mathrm{~Hz}$. It should be noted that the precise frequency of this concentrated acoustic power, and its level, varies with time, within this frequency range. Tonal components can also be seen outside of this frequency range, albeit being less readily discernible above the background noise. Periodicity in the spectral and amplitude components can be observed, particularly below $40 \mathrm{~Hz}$, and this is thought to be the result of tidal flow induced vibrations in the autonomous acoustic recorder housing/mounting. For this reason, analysis of tonal components thought to be associated with the turbine operation did not consider frequencies below $40 \mathrm{~Hz}$. This noise contamination is considered further in Sec. IV C.

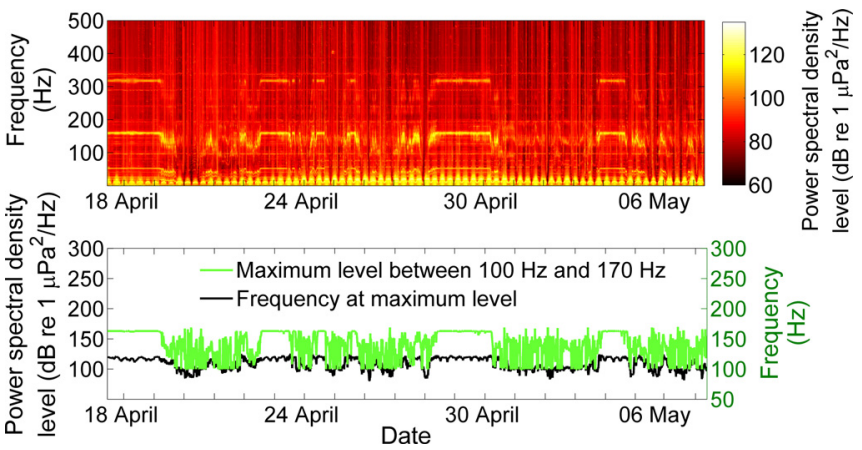

FIG. 4. (Color online) Spectrogram of underwater sound measured about $50 \mathrm{~m}$ from wind turbine A5 showing the frequency and amplitude during the 21-day deployment (top). The spectrogram display has been plotted up to $500 \mathrm{~Hz}$ for clarity. The lower panel shows the maximum mean-square sound pressure spectral density level (power spectral density level) between 100 and $170 \mathrm{~Hz}$ plotted alongside the corresponding frequency data. 
The lower panel in Figs. 3 and 4 shows the maximum power spectral density level, in a $1 \mathrm{~Hz}$ band, which falls in the frequency range between 100 and $170 \mathrm{~Hz}$. This is plotted alongside the frequency at which this maximum power spectral density level occurs. The data show that the most prominent tonal frequency component (highest amplitude of around $126 \mathrm{~dB}$ re $1 \mu \mathrm{Pa}^{2} \mathrm{~Hz}^{-1}$ and $124 \mathrm{~dB}$ re $1 \mu \mathrm{Pa}^{2} \mathrm{~Hz}^{-1}$, approximately $50 \mathrm{~m}$ from turbine $\mathrm{A} 1$ and $\mathrm{A} 5$, respectively) occurred at around $162 \mathrm{~Hz}$, for a $1 \mathrm{~Hz}$ resolution. For most of the time, the maximum level was below $120 \mathrm{~dB}$ re $1 \mu \mathrm{Pa}^{2} \mathrm{~Hz}^{-1}$. In general, the maximum power spectral density level associated with the turbine operation, and the corresponding frequency, was variable over the deployment period. Comparing Figs. 3 and 4 with Fig. 2, it can be seen that the highest power spectral density levels generally coincided with times of higher turbine operational rates. Conversely, the lowest power spectral density levels corresponded with measurement periods during reduced turbine operation.

For clarity, Figs. 3 and 4 only show the power spectral density levels up to $500 \mathrm{~Hz}$ as it was determined that most of the acoustic energy that could be associated with turbine operation occurred at frequencies below $500 \mathrm{~Hz}$. The elevated power spectral density levels seen at frequencies between 320 and $330 \mathrm{~Hz}$ are thought to be harmonics of the main tonal component at around $162 \mathrm{~Hz}$.

Figures 5-8 show the acoustical data, for turbine A1 and A5, presented as a function of frequency. The measurement data are shown as narrowband $(1 \mathrm{~Hz})$ meansquare sound pressure spectral density levels (power spectral density levels) in Figs. 5 and 6, and as mean-square sound pressure spectral levels (power spectral levels) in one-third octave bands in Figs. 7 and 8, to facilitate comparison with previous data. Figures 7 and 8 show data for the maximum measurement bandwidth identified in Sec. II C. For enhanced detail, power spectral density levels (Figs. 5 and 6) are plotted for a narrower bandwidth, between 40 and $400 \mathrm{~Hz}$.

To obtain the sound levels corresponding to a particular turbine operating state, the spectra were pooled into categories

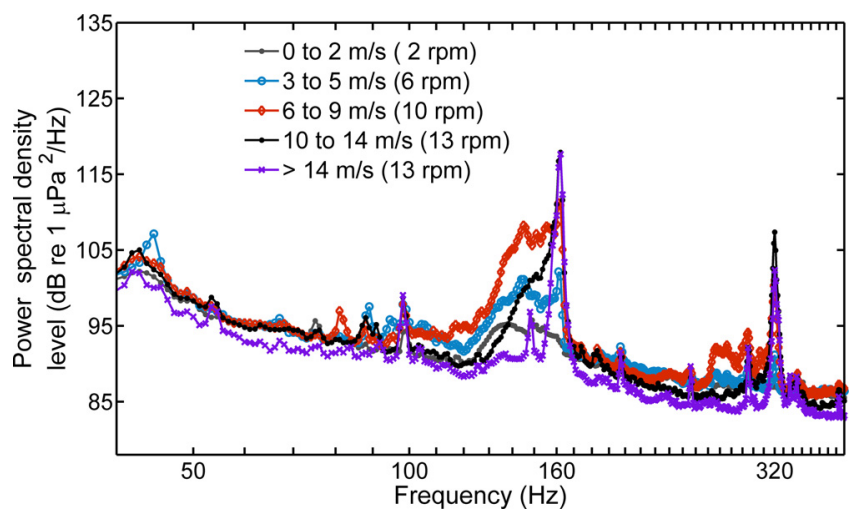

FIG. 5. (Color online) Time-averaged spectral characteristics of underwater noise measured around $50 \mathrm{~m}$ from wind turbine A1. The data are shown as mean-square sound pressure spectral density (power spectral density) levels between 40 and $400 \mathrm{~Hz}$. The horizontal axis tick marks occur at $10 \mathrm{~Hz}$ intervals. The data are presented for five categories of wind speed conditions: $0-2 \mathrm{~ms}^{-1}, 3-5 \mathrm{~ms}^{-1}, 6-9 \mathrm{~ms}^{-1}, 10-13 \mathrm{~ms}^{-1}$, and $>14 \mathrm{~ms}^{-1}$. The corresponding mean rotor speed (rpm) is stated in brackets.

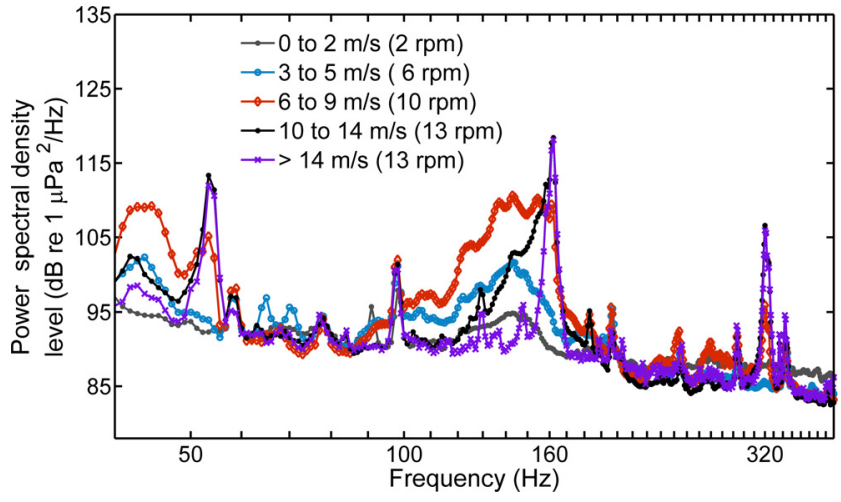

FIG. 6. (Color online) Time-averaged spectral characteristics of underwater noise measured around $50 \mathrm{~m}$ from wind turbine A5. The data are shown as mean-square sound pressure spectral density (power spectral density) levels between 40 and $400 \mathrm{~Hz}$. The horizontal axis tick marks occur at $10 \mathrm{~Hz}$ intervals. The data are presented for five categories of wind speed conditions: $0-2 \mathrm{~ms}^{-1}, 3-5 \mathrm{~ms}^{-1}, 6-9 \mathrm{~ms}^{-1}, 10-13 \mathrm{~ms}^{-1}$, and $>14 \mathrm{~ms}^{-1}$. The corresponding mean rotor speed (rpm) is stated in brackets.

based on wind speed ranging from 0 to $25 \mathrm{~ms}^{-1}$ (excluding wind speeds above the cut-off wind speed of the turbine). The average narrowband power spectral density levels and the average one-third octave band spectral levels are shown for five nominal wind speed categories: 0 to $2 \mathrm{~ms}^{-1} ; 3$ to $5 \mathrm{~ms}^{-1}$; 6 to $9 \mathrm{~ms}^{-1} ; 10$ to $14 \mathrm{~ms}^{-1}$; and $>14 \mathrm{~ms}^{-1}$. These categories were chosen to represent nominal turbine operating parameters related to wind speed, such as the cut-in and cut-out wind speed, and the optimal rated power envelope. The average was obtained for the mean-square sound pressure in each $1 \mathrm{~Hz}$ bin and one-third octave bands which occurred for each of these categories over the entire deployment period. The presented average sound levels therefore include measurements of the turbine operating in response to the given wind speed categories for a range of environmental (e.g., tidal height, swell, weather, etc.) and external factors (e.g., presence of other noise sources such as service vessels). The minimum duration on which this average was based was for $54 \mathrm{~h}$ of data, and this resulted from the highest wind speed category.

The average power spectral density levels in each of the wind speed categories, measured approximately $50 \mathrm{~m}$ from

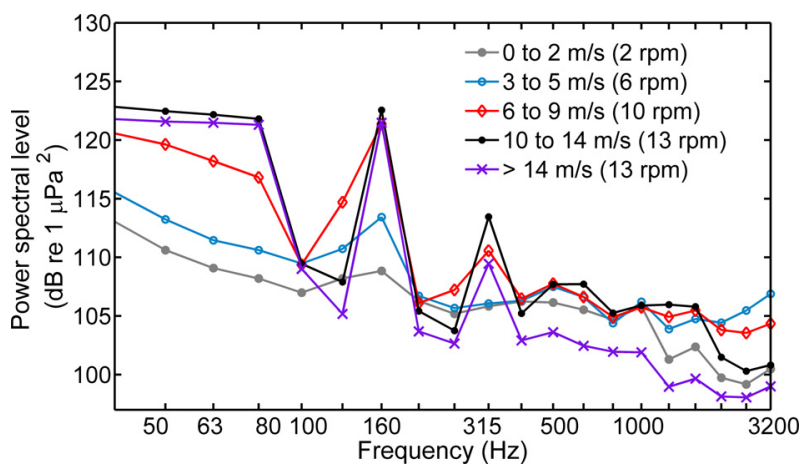

FIG. 7. (Color online) The average measured mean-square sound pressure spectral level (power spectral level) shown for one-third octave bands between 40 and $3200 \mathrm{~Hz}$. The data were measured at turbine A1 over 21 days, and are presented for five categories of wind speed conditions: $0-2 \mathrm{~ms}^{-1}, 3-5 \mathrm{~ms}^{-1}, 6-9 \mathrm{~ms}^{-1}, 10-13 \mathrm{~ms}^{-1},>14 \mathrm{~ms}^{-1}$. The corresponding mean rotor speed (rpm) is stated in brackets. 


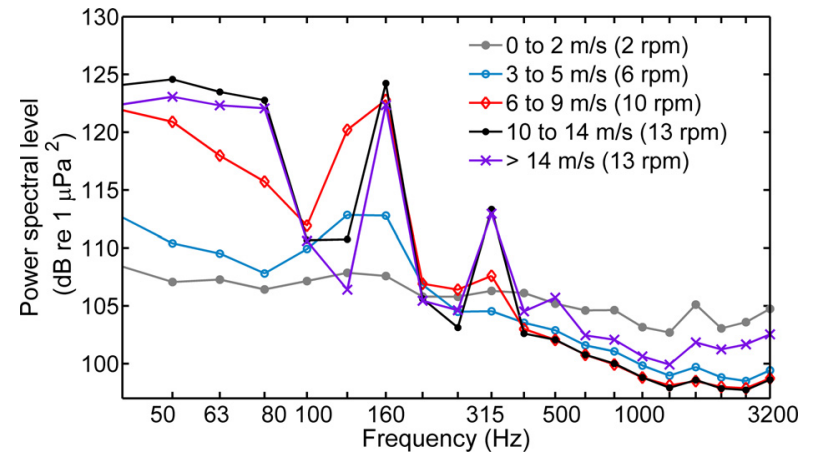

FIG. 8. (Color online): The average measured mean-square sound pressure spectral level (power spectral level) shown for one-third octave bands between 40 and $3200 \mathrm{~Hz}$. The data were measured at turbine A5 over 21 days, and are presented for five categories of wind speed conditions: $0-2 \mathrm{~ms}^{-1}, 3-5 \mathrm{~ms}^{-1}, 6-9 \mathrm{~ms}^{-1}, 10-13 \mathrm{~ms}^{-1},>14 \mathrm{~ms}^{-1}$. The corresponding mean rotor speed (rpm) is stated in brackets.

the turbine, shown in Figs. 5 and 6 increased from approximately $101 \mathrm{~dB}$ re $1 \mu \mathrm{Pa}^{2} \mathrm{~Hz}^{-1}$ at a frequency of $162 \mathrm{~Hz}$ in the 3 to $5 \mathrm{~ms}^{-1}$ category to approximately $118 \mathrm{~dB}$ re $1 \mu \mathrm{Pa}^{2} \mathrm{~Hz}^{-1}$ at a frequency of $162 \mathrm{~Hz}$ in the $>14 \mathrm{~ms}^{-1}$ category, for turbine A1 (see Fig. 5). Similarly, for turbine A5 (see Fig. 6), the average power spectral density level measured in this band increased from approximately $94 \mathrm{~dB}$ re $1 \mu \mathrm{Pa}^{2} \mathrm{~Hz}^{-1}$ at $162 \mathrm{~Hz}$ in the 3 to $5 \mathrm{~ms}^{-1}$ category to approximately $118 \mathrm{~dB}$ re $1 \mu \mathrm{Pa}^{2} \mathrm{~Hz}^{-1}$ at $162 \mathrm{~Hz}$ in the $>14 \mathrm{~ms}^{-1}$ category; $3 \mathrm{~ms}^{-1}$ is the turbine cut-in wind speed, and the turbine cuts out at $25 \mathrm{~ms}^{-1}$.

Figures 7 and 8 show the same data as that shown in Figs. 5 and 6, respectively, but converted into the one-third octave band power spectral levels, and are extended in frequency range to include the maximum available frequency measured.

In the narrowband analysis shown in Figs. 5 and 6, it can be seen that at all wind speed categories, except for the maximum $\left(>14 \mathrm{~ms}^{-1}\right)$, the power spectral density level is spread over a broader range of frequencies, extending below that of the frequency at which the maximum power spectral density level occurs. Closer inspection of the data, particularly of the spectrograms shown in Figs. 3 and 4 and comparison of these with Fig. 2 for turbines A1 and A5, indicates that there is a noticeable variability in the tonal signals generated at the lower wind speeds, which when averaged for all the measurement data for a given wind speed category manifest as a spreading across bands, for $1 \mathrm{~Hz}$ bands as in Figs. 5 and 6, and for one-third octave bands as in Figs. 7 and 8 . When analysed in one-third octave bands, the spreading of this acoustic power means that there is potential for the power spectral level in the $160 \mathrm{~Hz}$ band to be higher for the 10 to $14 \mathrm{~ms}^{-1}$ wind speed category than the highest wind speed category, despite the latter being associated with the maximum narrowband power spectral density level. The reason for this variability in frequency characteristics when the wind turbine generator power is ramping up is not clear. The wind turbine considered in this study is described in Sec. II A, and it should be noted that the turbine is designed to have a maximum rotor speed of $13 \mathrm{rpm}$. The turbine will regulate this at wind speeds above the wind speed at which it is rated for nominal power by adjustment of the turbine blade pitch, i.e., above a certain wind speed the rotor speed will not increase. The maximum rotor speed will result in a fundamental frequency around $0.2 \mathrm{~Hz}$, with potential for higher frequencies resulting from the gear meshing and generator operation. The generator operated at speeds up to around $1640 \mathrm{rpm}$ which would be expected to produce a fundamental frequency component of around $27 \mathrm{~Hz}$, with potential for harmonics of this fundamental frequency. Whilst it is difficult to identify what gearbox mesh frequencies would be generated without a detailed understanding of the gearbox, it is likely that the frequency component around $162 \mathrm{~Hz}$ originated from the gearbox.

When analysed in one-third octave bands, there is very little broadband increase in the power spectral level, with most of the increase occurring only in the $160 \mathrm{~Hz}$ band. However, when compared with the narrowband analysis it can be seen that there are a number of frequencies which increase with wind speed or generator speed, in addition to the dominant frequency component around $162 \mathrm{~Hz}$. The tonal frequency components are important characteristics of the sound radiated into the water, which increase notably with wind speed and generator speed, and much of this information is lost when analysed and displayed in one-third octave bands.

The broadband root-mean-square sound pressure level (hereafter SPL), calculated as described in Sec. III A, is shown as a function of integer wind speed bins between 0 and $28 \mathrm{~ms}^{-1}$ in Figs. 9 and 10, for turbine A1 and A5, respectively. The figures show an initial general increase in the SPL from a wind speed of 1 to $4 \mathrm{~ms}^{-1}$. This increase may be due to an increase in wind driven sea-state. The SPL values at wind speeds below $1 \mathrm{~ms}^{-1}$ are anomalous as they would be expected to be lower in value. It is possible that this is noise radiated from the turbine whilst it is not operational. Another possible explanation for the elevated SPL at wind speeds below $1 \mathrm{~ms}^{-1}$ could include a potential increase in vessel activity around the wind farm during calm conditions. For both turbines, a step increase in the SPL was observed between 4 and $5 \mathrm{~ms}^{-1}$, which is expected to be related to the wind turbine commencing to produce power. For this specific wind turbine, a wind speed of between 3 and $5 \mathrm{~ms}^{-1}$ is required to generate power (cut-in speed).

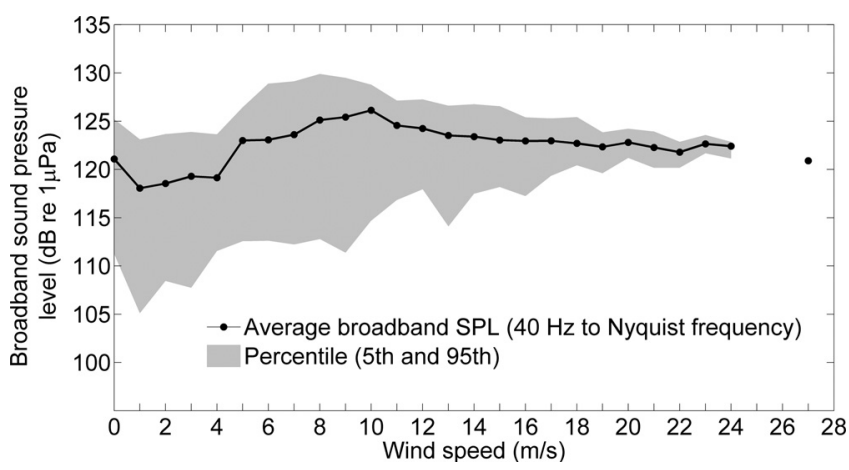

FIG. 9. Broadband sound pressure level (SPL) as a function of wind speed shown as the average, and the $5 \%$ and $95 \%$ percentile for wind turbine A1. The wind speed is pooled in $1 \mathrm{~ms}^{-1}$ bins, and the SPL is calculated between $40 \mathrm{~Hz}$ and the Nyquist frequency, and averaged over a $10 \mathrm{~min}$ period. A single data point was available for wind speeds exceeding $25 \mathrm{~ms}^{-1}$. 


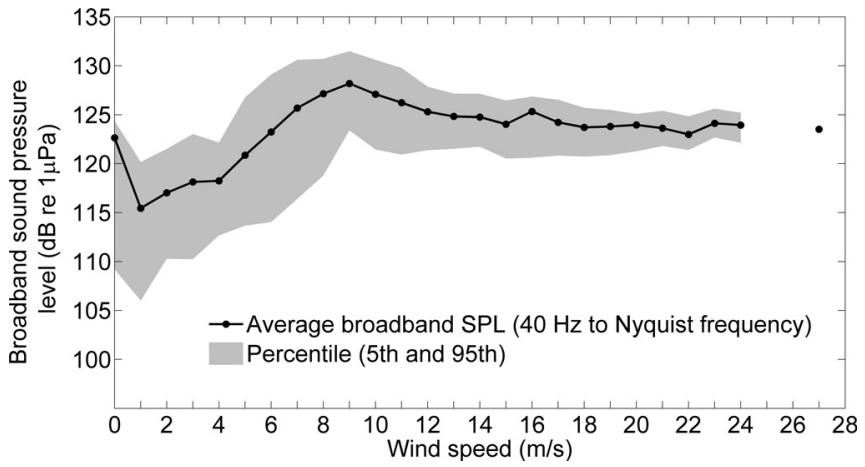

FIG. 10. Broadband sound pressure level (SPL) as a function of wind speed shown as the average, and the $5 \%$ and $95 \%$ percentile for wind turbine A5. The wind speed is pooled in $1 \mathrm{~ms}^{-1}$ bins, and the SPL is calculated $40 \mathrm{~Hz}$ and the Nyquist frequency. A single data point was available for wind speeds exceeding $25 \mathrm{~ms}^{-1}$.

Beyond this, there is a general increase in the SPL with increasing wind speed. This peaks at a wind speed of around 9 to $10 \mathrm{~ms}^{-1}$, before the SPL begins to show a gradual decreasing trend with increasing wind speed. The SPL reaching its maximum around a wind speed of 9 to $10 \mathrm{~ms}^{-1}$ can be explained by the relationship between the wind speed and the rotor speed, and the generator speed. Figures 11 and 12, show plots of the generator speed and rotor speed as a function of wind speed for turbines A1 and A5, respectively. These plots indicate that at a wind speed of around $7 \mathrm{~ms}^{-1}$, the rotor and the generator broadly reach their maximum rotational speed and appear to plateau beyond a wind speed of around 11 to $12 \mathrm{~ms}^{-1}$. This does not, however, explain the decrease in the SPL beyond 9 to $10 \mathrm{~ms}^{-1}$ winds. The narrowband analysis, used to construct Figs. 5 and 6, and which is provided in the supplementary material, ${ }^{1}$ shows that the highest mean-square sound pressure spectral density levels occur at a wind speed of about 12 to $14 \mathrm{~ms}^{-1}$. This is consistent with what might be expected from the turbine design specification, which states that the nominal maximum power output of this type of turbine is achieved at a wind speed of 13 to $14 \mathrm{~ms}^{-1}$. Without a detailed knowledge of the gearbox operation and its behaviour under different operating conditions, it is not possible to provide a detailed analysis, with
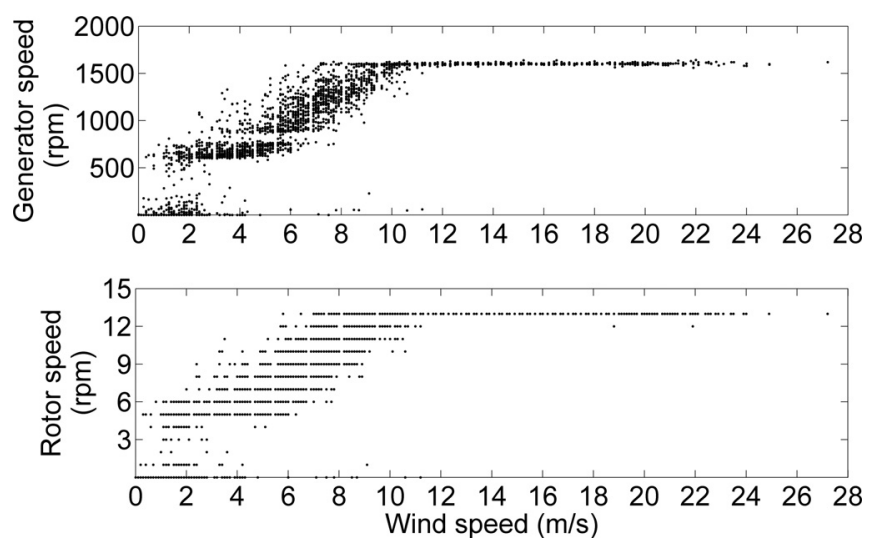

FIG. 11. Wind turbine rotor and generator speed plotted as a function of wind speed, for wind turbine A1. The rotor speed and the generator speed data were available as integer values, and the wind speed to one decimal place.
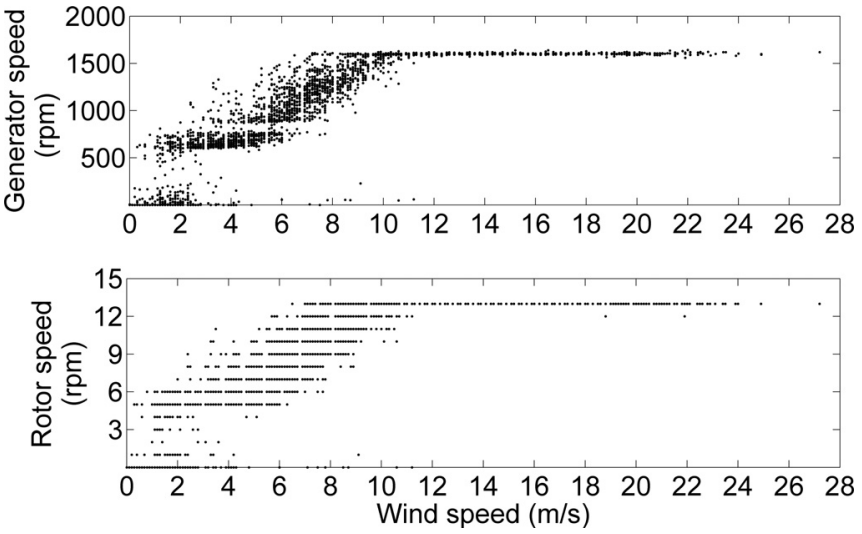

FIG. 12. Wind turbine rotor and generator speed plotted as a function of wind speed, for wind turbine A5. The rotor speed and the generator speed data were available as integer values, and the wind speed to one decimal place.

any certainty, on the causes of the complex tonal characteristics of the acoustic data. It should also be noted that the characteristics of the sound radiated into the water are tonal in nature, and the broadband SPL is a simplistic way of assessing the total sound output as a function of wind speed. The mean-square sound pressure spectral density levels shown in Figs. 5 and 6, and provided in the supplementary material, ${ }^{1}$ are expected to be more informative.

\section{DISCUSSION}

\section{A. Applicability of data}

The acoustical data from the two offshore wind turbines measured as part of this study show apparent differences between the two nominally identical turbines, which cannot be easily described by differences in the foundation which are very similar, the substrate in which the foundation terminates, nor the acoustic propagation. The differences are evident in the tonal characteristics of each of the turbines, particularly around wind speeds between 6 and $9 \mathrm{~ms}^{-1}$. Whilst it is not possible to be certain, it is thought that this is due to slight differences in the gearboxes operation or the power regulation of the two turbines. Turbine A1, which shows higher mean-square sound pressure spectral levels at frequencies above a few hundred hertz, was understood by the authors to have reported operational errors to the wind farm control centre, although the nature of the error is unknown. This indicates that nominally identical turbines, operating within the same wind farm or similar environmental conditions, at the same rotational speed, etc., cannot be assumed to be acoustically identical. Despite this, the overall levels measured at the turbines are similar, and the tonal characteristics at the optimal operating power are comparable between the turbines. It should be noted that differences between the turbines might be expected due to differences in the measurement set-up (variability in position and depth of the acoustic recorders), system characteristics, water depth, operational state of neighbouring turbines, and the presence of vessels, etc. Whilst the agreement between the two turbines is relatively good, the presented data do show differences between the turbines and can only be considered to 
be representative for the turbines as measured. Care should be taken if extrapolating these data to be representative of operational offshore wind turbines, or indeed a Siemens SWT-3.6-107 turbine. Other studies have shown that the foundation type is an influencing factor on the acoustic characteristics of the sound radiated from the structure (Marmo et al., 2013; Norro et al., 2015), and alternate turbine types would also be expected to have notably different characteristics. For example, for turbine types that operate at a constant rate of revolution, the spectral characteristics of the turbine noise would be expected to remain relatively constant, with only the level varying with wind speed. This has been reported by Tougaard et al. (2009) for empirical data, and shown by Marmo et al. (2013) using numerical modelling. Sigray and Andersson (2011) reported a change in the turbine output characteristics in relation to its operational state. They observed the largest amplitudes for a moderate wind speed at $6 \mathrm{~ms}^{-1}$ rather than at full operating wind speed, which differs from the findings of Lindell (2003) who obtained measurements at the same site, and found the highest levels to correspond with wind speed. Sigray and Andersson (2011) suggested a gearbox replacement as the most likely explanation for this discrepancy.

\section{B. Contributing environmental variability}

Other than the expected measurement uncertainties, the key factors which would have caused variability in the data presented here are the background noise, tidal variations, and the presence of vessels in the vicinity. As ambient noise is expected to increase with surface agitation and thus wind speed (Wenz, 1962), it is likely that the ambient noise will increase as the generating output, and therefore the radiated noise, of the wind turbines increases. This has been shown by Tougaard et al. (2009) who reported higher signal-tonoise ratio between turbine and background noise for calmer weather and wind speed conditions, rather than in the case where highest turbine noise levels were reported. However, it should be noted that this was only reported in terms of one-third octave bands and the change in signal-to-noise ratio may differ for narrowband analysis where a tonal signal might be expected to show a greater increase relative to the ambient noise. Despite the measurement system having a sufficiently low noise floor, it was not possible in the measurements reported in this paper to observe a significant difference in the ambient noise which could be attributed to the wind speed. It is possible this is due to sea-state not being the dominant contributor to the ambient noise in the study location during the time of the measurements and over the frequency bandwidth used. Tidal height variation would also be expected to effect the amount of sound energy radiated into the water by varying the extent of the foundation and transition piece exposed to the water column. The measurement arrangement used here, i.e., one measurement depth and position, was insufficient to establish any difference due to tidal height. It should also be noted that local vessel activity, in particularly the wind farm service vessels, was also related to the tidal height due to access to the local port being tidal limited.

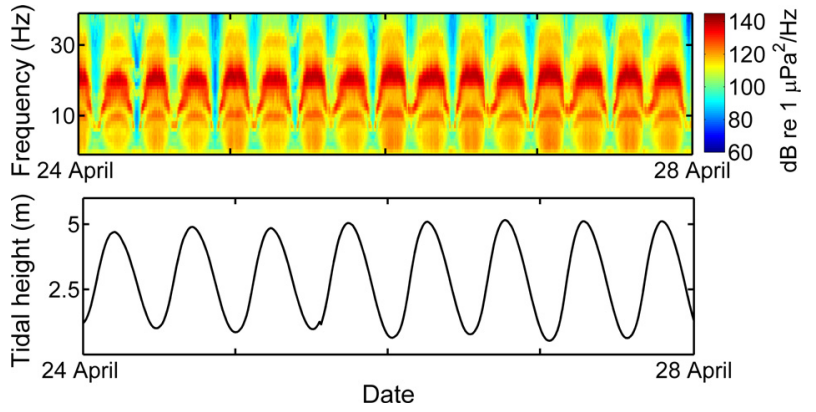

FIG. 13. (Color online) Spectrogram of underwater acoustical data measured at turbine A1 with tidal data plotted for comparison. The data are shown below $40 \mathrm{~Hz}$, and zoomed-in on a 4 day section for greater detail. The tidal data were obtained from a British Oceanographic Data Centre tidal gauge for Cromer. This is located some distance from the wind farm, and would not be expected to be perfectly time-synchronised with the tidal conditions at the wind farm. However, general temporal character may be compared. The elevated noise levels are thought to correspond to the tidal flow during ebb and flood tide. The tidal data are shown at $15 \mathrm{~min}$ resolution.

\section{Tidal flow induced noise}

The tide did, however, have a significant effect on the background noise, with peaks in the noise spectra, particularly below around $40 \mathrm{~Hz}$ being correlated with the tidal changes, as shown in Fig. 13. This shows low frequency sound fluctuations generally corresponding with the periodic nature and duration of the ebb and flow tide, interspersed with relatively short periods of reduced sound levels that were of similar duration as periods with low tidal flow (peak and low tide). This is strongly believed to be a result of the tidal flow on the measurement system, specifically flow induced vibrations in either the mounting system, or the hydrophone support, and not a result of changes in the ambient noise nor radiated noise from the turbine, and cannot be correlated with vessel activity.

\section{Limitations related to seabed vibration and sound particle motion}

Other routes for turbine noise to enter the water column may be through the air-water interface or through the seabed-water interface. For wind turbine foundations terminated in the seabed, structural vibrations will be expected to transmit into the water via the seabed. However, the measurement data presented here were measured in close proximity to the turbine and so propagating waves in the water column, which originate in the seabed, would not be expected, although the detection of pressure variation from low-frequency interface waves in the seabed cannot be ruled out. Furthermore, the sound particle motion was not measured, which is an important consideration when assessing noise impacts on marine fish and invertebrates, known to respond to particle motion (Popper et al., 2014; Mooney et al., 2010).

\section{CONCLUSIONS}

Underwater sound measurement data are presented from two 3.6 MW, Siemens SWT-3.6-107, operational wind 
turbines over their full operating envelope from the cut-in wind speed, through ramp up of the turbine output power, to its maximum operating power and its cut-out wind speed, obtained over a period of 21 days, in a water depth of about $20 \mathrm{~m}$, with the monopole turbine foundation terminating in a layer of chalk. The data show that the sound radiated into the water was characterised by a number of tonal components, within the measurement bandwidth, primarily related to the gearbox, with variation in amplitude which varied with wind speed, and thus rotor, and generator speed. Measured about $50 \mathrm{~m}$ from turbine $\mathrm{A} 1$ and $\mathrm{A} 5$, the maximum mean-square sound pressure spectral density level at around $162 \mathrm{~Hz}$ was $126 \mathrm{~dB}$ re $1 \mu \mathrm{Pa}^{2} \mathrm{~Hz}^{-1}$, and $124 \mathrm{~dB}$ re $1 \mu \mathrm{Pa}^{2} \mathrm{~Hz}^{-1}$, respectively. Other tonal components were also present, notably at frequencies between about 20 and $330 \mathrm{~Hz}$, albeit at lower amplitudes. An average broadband sound pressure level of $126 \mathrm{~dB}$ re $1 \mu \mathrm{Pa}$ and $128 \mathrm{~dB}$ re $1 \mu \mathrm{Pa}$ was calculated at wind speeds around $10 \mathrm{~ms}^{-1}$ for turbine A1 and A5, respectively, with corresponding 5th and 95th percentile values of 114 and $129 \mathrm{~dB}$ re $1 \mu \mathrm{Pa}$ and 123 and $131 \mathrm{~dB}$ re $1 \mu \mathrm{Pa}$. The measurements show that the sound radiated into the water and the spectral characteristics of the sound are dependent on the operating parameters of the wind turbine, i.e., the rotor and generator rotational speed resulting from variations in the wind speed. Across the operational envelope of the turbine, a change in the mean-square sound pressure spectral density level as high as $20 \mathrm{~dB}$ and higher was observed. No broadband sound in the data could be attributed to the wind turbine noise. Above the cut-in wind speed, the sound pressure level and mean-square sound pressure spectral density level increase with the wind speed, until the turbine approaches its nominal power rating. At around $13 \mathrm{~ms}^{-1}$ wind speeds the mean-square sound pressure spectral density levels of the main tonal peaks more or less plateau, and the sound pressure levels shows a gradual decrease with wind speed beyond about 9 or $10 \mathrm{~ms}^{-1}$ wind speed. The differences in the measured sound radiated from the two turbines indicates that caution is required if assuming that nominally identical wind turbines within a wind farm are acoustically identical, although the overall measured levels were similar.

\section{ACKNOWLEDGMENTS}

This work was commissioned by Scira in relation to a license requirement. We thank Statoil and Statkraft, Scira's parent companies, and Scira with its contractors, for logistical and technical support during instrument deployment, provision of site specific operational and environmental data, and permission to publish the underwater measurement data. Funding for the preparation of the manuscript was provided by the Department for Business, Energy and Industrial Strategy (BEIS) through the National Measurement System Programme for Acoustics and Ionising Radiation Metrology.

\footnotetext{
${ }^{1}$ See supplementary material at http://dx.doi.org/10.1121/1.4964824 for tabulated mean-square sound pressure density levels for each integer wind speed, and provided for each of the two turbines individually.
}

American National Standards Institute (1986). ANSI S1.11-1986 (ASA 651986), Specifications for Octave-Band and Fractional-Octave-Band Analog and Digital Filters (Acoustical Society of America, New York).

Betke, K., Schultz-von Glahn, M., and Matuschek, R. (2004). "Underwater noise emissions from offshore wind turbines," in Proceedings of CFA/ $D A G A^{\prime} 04$, Strasburg, 2 pp., available at http://www.conforg.fr/ cfadaga2004/master_cd/cd1/articles/000516.pdf.

Bilgili, M., Yasar, A., and Simsek, E. (2011). "Offshore wind farm development in Europe and its comparison with onshore counterpart," Renew. Sust. Energ. Rev. 15, 905-915.

Cheesman, S. (2016). "Measurements of operational wind turbine noise in UK waters," in Effects of Noise on Aquatic Life II. Advances in Experimental Medicine and Biology, edited by A. N. Popper and A. Hawkins (Springer, New York), Vol. 875, pp. 153-160.

Degn, U. (2000). "Offshore wind turbines - VVM, underwater noise measurements, analysis, and predictions," Odegaard \& Danneskiold-Samsoe A/ S, Report No. 00-792 rev.1, 29 pp.

European Council (1992). Council Directive 92/43/EEC of 21 May 1992 on the conservation of natural habitats and of wild fauna and flora, Official Journal L 206.

European Parliament and Council (2008). Directive 2008/2056/EC of the European parliament and of the council of 17 June 2008 establishing a framework for community action in the field of marine environmental policy (Marine Strategy Framework Directive) (Brussels, Belgium).

Global Wind Council (2015). "Global wind report: Annual market update 2015," report (Global Energy Wind Council, Brussels, Belgium).

Hayman, G., Robinson, S. P., and Lepper, P. A. (2016). "The calibration and characterisation of autonomous recorders used in measurement of underwater noise," in Effects of Noise on Aquatic Life II. Advances in Experimental Medicine and Biology, edited by A. N. Popper and A. Hawkins (Springer, New York), Vol. 875, pp. 441-445.

International Electrotechnical Commission (IEC) 60565 (2006). "Underwater acoustics-Hydrophones-Calibration in the frequency range $0.01 \mathrm{~Hz}$ to $1 \mathrm{MHz}$ " (International Electrotechnical Commission, Geneva, Switzerland).

ISO (2016). ISO DIS2 18405.02 "Underwater acoustics-Terminology" (International Organization for Standardization, Geneva, Switzerland).

Koschinski, S., Culik, B., Henriksen, O. D., Tregenza, N., Ellis, G., Jansen, C., and Kathe, G. (2003). "Behavioural reactions of free-ranging porpoises and seals to the noise of a simulated $2 \mathrm{MW}$ wind power generator," Mar. Ecol. Prog. Ser. 265, 263-273.

Lindell, H. (2003). "Utgrunden off-shore wind farm- Measurements of underwater noise," Report No. 11-00329-03012700 (Ingemansson Technology AB, Gothenburg, Sweden), 30 pp.

Madsen, P. T. (2005). "Marine mammals and noise: Problems with root mean square sound pressure for transients," J. Acoust. Soc. Am. 117, 3952-3957.

Madsen, P. T., Wahlberg, M., Tougaard, J., Lucke, K., and Tyack, P. (2006). "Wind turbine underwater noise and marine mammals: Implications of current knowledge and data needs," Mar. Ecol. Prog. Ser. 309, 279-295.

Marmo, B., Roberts, I., Buckingham, M. P., King, S., and Booth, C. (2013). Modelling of Noise Effects of Operational Offshore Wind Turbines Including Noise Transmission Through Various Foundation Types (Scottish Government, Edinburgh Scotland), 100 pp.

Mooney, T. A., Hanlon, R. T., Christensen-Dalsgaard, J., Madsen, P. T., Ketten, D. R., and Nachtigall, P. E. (2010). "Sound detection by the longfin squid (Loligo pealeii) studied with auditory evoked potentials: Sensitivity to low-frequency particle motion and not pressure," J. Exp. Biol. 213, 3748-3759.

Nedwell, J. R., Brooker, A. G., Edwards, B., and Bird, H. (2011a). "Subsea operational noise assessment of the Gunfleet Sands offshore wind farm," Subacoustech Report No. E267R0103 (Report to COWRIE Ltd.), 51 pp.

Nedwell, J. R., Brooker, A. G., Edwards, B., and Bird, H. (2011b). Subsea Operational Noise Assessment of the Lynn and Inner Dowsing Offshore Wind Farm Sites, Subacoustech Report No. E273R0118 (Report to COWRIE Ltd.), $30 \mathrm{pp}$.

Nedwell, J. R., Nedwell, J. R., and Howell, D. (2004). "A review of offshore windfarm related underwater noise sources," Subacoustech Report No. 544R0308 (Report to COWRIE Ltd.), 57 pp.

Nedwell, J. R., Parvin, S. J., Edwards, B., Workman, R., Brooker, A. G., and Kynoch, J. E. (2007). "Measurement and interpretation of underwater noise during construction and operation of wind farms in UK waters," Subacoustech Report No. 544R0738 (Report to COWRIE Ltd.), 80 pp. 
Norro, A., Rumes, B., and Degraer, S. (2015). "Characterisation of the operational noise, generated by offshore wind parks in the Belgian part of the North Sea," in UACE2015 Conference Proceedings - 3rd Underwater Acoustics Conference and Exhibition, Crete, Greece, pp. 507-514.

Popper, A. N., Hawkins, A. D., Fay, R. R., Mann, D., Bartol, S., Carlson, Th., Coombs, S., Ellison, W. T., Gentry, R., Halvorsen, M. B., Lokkeborg, S., Rogers, P., Southall, B. L., Zeddies, D. G., and Tavolga, W. N. (2014). ASA S3/SC1.4 TR-2014, Sound Exposure Guidelines for Fishes and Sea Turtles (Springer and ASA Press, Cham, Switzerland).

RenewableUK (2015). "UK Wind Energy Database (UKWED)," http:// www.renewableuk.com/en/renewable-energy/wind-energy/uk-wind-energy database/index.cfm (Last viewed December 16, 2015).

Sigray, P., and Andersson, M. H. (2011). "Particle motion measured at an operational wind turbine in relation to hearing sensitivity in fish," J. Acoust. Soc. Am. 130, 200-207.

Thomsen, F., Lüdemann, K., Kafemann, R., and Piper, W. (2006). "Effects of offshore wind farm noise on marine mammals and fish," Report (Biola, Hamburg, Germany), 62 pp.
Tougaard, J., Henriksen, O. D., and Miller, L. A. (2009). "Underwater noise form three types of offshore wind turbines: Estimation of impact zones for harbor porpoises and harbor seals," J. Acoust. Soc. Am. 125, 3766-3773.

Wahlberg, M., and Westerberg, H. (2005). "Hearing in fish and their reactions to sounds from offshore wind farms," Mar. Ecol. Prog. Ser. 288, 295-309.

Welch, P. D. (1967). "The use of fast Fourier transform for the estimation of power spectra: A method based on time averaging over short, modified periodograms," IEEE Trans. Aud. Electr. 15, 70-73.

Wenz, G. M. (1962). "Acoustic ambient noise in the ocean: Spectra and sources," J. Acoust. Soc. Am. 34, 1936-1955.

Westerberg, H. (1994). "Fiskeriundersökningar vid havsbaserade vindkraftverk 1990-1993" ("Fisheries Investigations at offshore wind farms 19901993”), Fisk. Utredningskont. Jön. Rapp. 5, 44, available at http://space.hgo. se/wpcvi/wp-content/uploads/import/pdf/Kunskapsdatabas\%20miljo/Flora $\% 20$ och\%20fauna/marina\%20organismer/utredningar/Fiskeriundersokn \%20vid\%20Svante\%20I\%201990_1993\%20optimerad\%20version.pdf. 